ARTIGOS

\title{
EMPREENDEDORISMO SUSTENTÁVEL: ESTUDO MULTICASO DA IMPLEMENTAÇÃO DA SUSTENTABILIDADE EM EMPRESAS INCUBADAS
}

\section{RESUMO}

O estudo multicaso procurou analisar a incorporação das dimensões da sustentabilidade empresarial em empresas incubadas, verificando a compreensão dos empreendedores quanto à sustentabilidade empresarial e identificando, entre as dimensões social e ambiental da sustentabilidade, qual predomina como preocupação emergente. Trata-se de uma pesquisa exploratória-descritiva. A partir da pesquisa bibliográfica realizada, um roteiro de entrevista foi desenvolvido, estruturado sobre quatro construtos. Foram entrevistados três dos quatro empreendedores atendidos pelo PARTEC, incubadora de empresas do NUTEC, visando a ampliar os achados da revisão bibliográfica. Verificou-se que a definição de sustentabilidade empresarial mais aceita se refere apenas às dimensões econômica e ambiental, ficando a social em segundo plano. Entretanto, perceberam-se dificuldades na compreensão do tema entre os consultados. Os empreendedores priorizam a dimensão ambiental sobre a social em suas atividades. As organizações não podem ser consideradas plenamente sustentáveis. Entretanto, pode-se afirmar que as soluções oferecidas por elas são sustentáveis, pois permitem a sobrevivência das organizações e da natureza, além de gerar impactos positivos e sustentáveis na sociedade.

Palavras-chave: Empreendedorismo Sustentável. Empresas incubadas. Estudo Multicaso.

\section{INTRODUÇÃO}

As constantes transformações no entorno em que vive o ho-

Themisa Araújo Barros Pimentel themisapimentel@gmail.com Bacharel em Administração pela Universidade Federal do Ceará. Gerente de Marketing da Devry Brasil - Fortaleza-CE-BR

Leonel Gois Lima Oliveira leonel.oliveira@fgv.br Doutor em Administração EBAPE/FGV e Professor da Esmec-Fortaleza-CE-BR mem moderno alteram frequentemente sua visão de mundo, sua forma de pensar e agir (DALMORO, 2009). Frente às mudanças climáticas e ao desequilíbrio de ecossistemas complexos, o ser humano torna-se consciente de que seu comportamento está afetando negativamente o meio ambiente. Por outro lado, o desequilíbrio na distribuição de renda no Brasil e no mundo, além das constantes tensões entre diferentes grupos sociais, étnicos e culturais, tem conduzido as sociedades a reflexões relacionadas à responsabilidade social (ROMANINI, 2007).

Para Almeida (2007), a percepção de que a responsabilida- 
de socioambiental é papel do governo mudou e estendeu-se a todos os setores. Neste contexto, começam a surgir pressões sociais, governamentais e mercadológicas a favor da incorporação do conceito de sustentabilidade aos negócios. Sob esse olhar, Silva e Tobias (2007) argumentam que a defesa de questões ideológicas, ambientais e sociais em campanhas publicitárias e de marketing de grandes empresas demonstra que tais organizações já perceberam e estão se adaptando às mudanças macroambientais. Além disso, Romanini (2007) declara que as pressões geradas por estas mudanças também afetam as pequenas e médias empresas, cuja sobrevivência não se resume mais a obter resultados financeiros positivos. É preciso não prejudicar o que está a seu redor e inserir-se em seu entorno, influenciando-o positivamente.

O governo incentiva a adoção de boas práticas socioambientais por pequenas e médias empresas, oferecendo maior disponibilidade de recursos, a taxas menores que as cobradas no mercado, e acesso a linhas especiais do Banco Mundial, do Banco Nacional de Desenvolvimento Econômico e Social (BNDES) e de outros bancos públicos. Christopher Wells, superintendente de risco socioambiental do Banco Real, corrobora com a importância da adoção destas práticas, afirmando que "o risco de não adotar práticas sustentáveis está ficando maior que o custo de adotá-las" (ROMANINI, 2007, p. 2).

Percebe-se a necessidade de incorporação da sustentabilidade aos processos de pequenas e médias empresas e as oportunidades abertas com a adoção de boas práticas socioambientais. Entretanto, é importante conhecer o que os empreendedores compreendem por sustentabilidade e o que realmente estão fazendo em direção ao desenvolvimento sustentável. Isto será fundamental para orientar futuras ações em prol da sustentabilidade no meio empresarial.

Cardoso et al. (2008) apontam que uma incubadora de tecnologia tem potencial para fomentar e induzir as empresas incubadas à abordagem do Desenvolvimento Sustentável. Entretanto, as iniciativas empreendedoras tendem a enfocar principalmente na elaboração de produtos que minimizem os impactos ambientais, mas que a sustentabilidade está longe de ser uma preocupação pelos responsáveis das incubadoras (BRITO; BRUNSTEIN; AMARO, 2014). Surge, então, o questionamento: a sustentabilidade está sendo incorporada nos micro, pequenos e médios empreendimentos incubados?

Sendo assim, este artigo tem como objetivo analisar a incorporação das dimensões da sustentabilidade empresarial nas empresas industriais atendidas pelo Parque Tecnológico do NUTEC (PARTEC), incubadora de empresas da Fundação Núcleo de Tecnologia Industrial do Ceará (NUTEC).

Para atingir estes objetivos, realizou-se uma pesquisa exploratório-descritiva. Inicialmente, recorreu-se à pesquisa bibliográfica para melhor compreender o tema Sustentabilidade Empresarial e para apoiar as análises dos dados coletados na pesquisa de campo. Realizou-se leitura crítica e reflexiva de livros, periódicos científicos, dissertações, anais de encontros acadêmicos e revistas de negócios relacionados ao problema investigado.

Foram entrevistados três dos quatro empreendedores incubados no PARTEC, com o objetivo de levantar compreensões e atitudes relacionadas à sustentabilidade empresarial. $\mathrm{O}$ PARTEC foi utilizado como campo empírico da pesquisa exploratória porque se acredita que uma incubadora de empresas é um ambiente propício para encontrar empreendedores mais abertos e interessados em adequar-se às mudanças macroambientais.

Quanto à estrutura do trabalho, inicia-se pela introdução, apresentando a problemática do estudo, o objetivo, assim como as linhas gerais da pesquisa realizada. O referencial teórico aborda os temas Empreendedorismo, Incubação de Empresas, Sustentabilidade nas Organizações e Empreendedorismo Sustentável, respectivamente; discutindo tópicos relevantes para responder à questão fundamental. Em seguida, a metodologia é explicada e os resultados analisados. As últimas seções apresentam a conclusão e as referências utilizadas. 


\section{EMPREENDEDORISMO E INCU- BAÇÃO DE EMPRESAS}

O empreendedorismo sempre esteve presente nas diversas comunidades e sociedades ao longo da história, apesar de divergir quanto a sua forma de manifestação. Vale ressaltar que o sucesso desta atividade está ligado à superação de riscos e restrições (MURPHY; LIAO; WELSCH, 2006). O termo empreendedor origina-se do francês Entrepreneur que significa "aquele que está entre", "intermediário" (HISRICH; PETERS, 2004). Em inglês, utiliza-se o vocábulo francês para denominar novos empresários e pessoas que se estabelecem por conta própria (DALMORO, 2009).

Segundo Dalmoro (2009), atualmente, há duas correntes de pensamento que abordam o conceito. A primeira é adotada por economistas e associa o empreendedor à inovação. Com relação à inovação, ainda se encontram diversas definições sobre o que se entende por Inovação Sustentável (PINSKY et al., 2015). Enquanto a segunda, adotada por comportamentalistas, concentra-se em seus aspectos criativo e intuitivo. O autor opta pela definição: "o empreendedor é compreendido como uma função composta de quatro elementos: traços de personalidade, propensão à inovação, propensão a assumir riscos e postura estratégica" (CARLAND; CARLAND; HOY, 1992 apud DALMORO, 2009, p. 91).

Hisrich e Peters (2004, p. 36) reconhecem que "pequenas firmas desempenham um papel importante na criação de empregos e na inovação". Esses autores ressaltam ainda que o empreendedorismo contribui com o desenvolvimento econômico por iniciar e constituir mudanças na estrutura do negócio e da sociedade, promovendo, assim, crescimento, aumento da produção e distribuição de renda.

A inovação é um fator importante no desenvolvimento de novos produtos para o mercado e também no incentivo ao investimento em novos empreendimentos. Assim, o crescimento econômico é estimulado com o desenvolvimento da inovação e sua comercialização através da atividade empresarial. Neste processo, é fundamental a combinação entre tecnologia/conhecimento e mercado/necessidades sociais. Toda inovação evolui e é comercializada através do governo, do intraempreendedorismo e do empreendedorismo (HISRICH; PETERS, 2004).

$\mathrm{O}$ empreendedorismo tem sido o método mais eficiente para ligar tecnologia e mercado, apesar das dificuldades do empreendedor quanto a habilidades administrativas, recursos financeiros e relacionamento com parceiros (HISRICH; PETERS, 2004).

Dornelas (2008) alerta que a criação de empresas não conduz, obrigatoriamente, ao desenvolvimento econômico, pois há dois tipos de empreendedorismo:

a) empreendedorismo de oportunidade - o empreendedor percebe uma oportunidade de negócio no mercado e cria uma empresa com planejamento prévio e objetivos claros para melhorar sua condição de vida. Esse tipo de empreendimento promove o desenvolvimento econômico por meio do crescimento da organização e da geração de lucro, empregos e riqueza;

b) empreendedorismo de necessidade - o empreendedor inicia suas atividades por falta de opção (desemprego) e cria uma empresa com pouco ou nenhum planejamento diante de uma necessidade. Estes negócios costumam ser informais e fracassam rapidamente, não contribuindo com o desenvolvimento econômico e agravando as estatísticas de criação e mortalidade de negócios. Esse tipo de empreendedorismo é mais comum em países em desenvolvimento.

Incubadora de empresas é um núcleo que abriga empresas de base tecnológica, normalmente de pequeno porte, para criar e/ou desenvolver estas organizações e/ou seus produtos - bens e serviços frequentemente inovadores e intensivos de conteúdo intelectual (AUDY et al., 2003).

A incubação de empresas pode ser subdividida em três fases essenciais: o período 
de pré-incubação, incubação e pós-incubação. $\mathrm{O}$ processo de incubação pode ocorrer interna (incubação interna ou residente) ou externamente (incubação à distância ou não residentes) (ABREU; SWIRSKI; GONÇALO, 2006; IACONO; ALMEIDA; NAGANO, 2011).

De acordo com NUTEC (2011) e Audy et al. (2003), as incubadoras exercem importantes papéis, como:

a) conscientização dos empreendedores incubados de que é possível produzir tecnologia nacional que atue como solução alternativa e, muitas vezes, mais vantajosa para as necessidades do mercado nacional;

b) produção de bens anteriormente importados, eliminando a necessidade de importação, seguindo a política do Ministério da Ciência e Tecnologia (MCT);

c) desenvolvimento de produtos e processos em condições especiais para competir com os mercados dos grandes blocos econômicos. Experiências realizadas em países desenvolvidos evidenciaram que a incubação de empresas é uma estratégia adequada para o desenvolvimento sustentável das nações;

d) desenvolvimento de negócios com grande potencial de sucesso, com boas condições de competir no mercado;

e) intercâmbio de ideias e tecnologias entre os empresários incubados, que aprendem a importância de compartilhar o mesmo espaço, realizar parcerias e cultivar relacionamentos de forma efetiva.

Cardoso et al. (2008) consideram que as incubadoras desenvolvem práticas organizacionais que incentivam o processo de aprendizagem e da criação de conhecimento. Dessa forma, elas podem contribuir como um forte mecanismo de indução ao desenvolvimento sustentável para as empresas que estão incubadas. Este fato permite ampliar a atuação das incubadoras no desenvolvimento regional, por ser uma instituição catalisadora de empreendi- mentos bem-sucedidos (VEDOVELLO, 2000).

O Brasil passa por uma fase muito favorável ao empreendedorismo, destacando-se o crescimento do empreendedorismo por oportunidade. O estudo realizado pelo Global Entrepreneurship Monitor (GEM) em 2008 classifica o país na $13^{a}$ posição do ranking mundial de empreendedorismo, afirmando que, para cada grupo de 100 brasileiros em idade adulta (18 a 64 anos), 12 realizam alguma atividade empreendedora (GRECO, 2009). Além disso, em 2007 , aproximadamente $57 \%$ dos empreendimentos brasileiros foram classificados como empreendedorismo de oportunidade e os $43 \%$ restantes como empreendedorismo de necessidade (DORNELAS, 2008). Já em 2008, o Brasil chegou à razão de dois empreendedores por oportunidade para cada empreendedor por necessidade (GRECO, 2009).

Observa-se também que a atividade empreendedora nacional já atingiu certo nível de maturidade, pois a taxa de sobrevivência de micro e pequenas empresas aumentou: em 2002, 50,6\% destas empresas sobrevivia pelo menos dois anos; em 2005, o percentual passou para 78\% (SEBRAE, 2007). Portanto, $27,4 \%$ a mais de micro e pequenas empresas permanecem em atividade.

Dessa forma, será que os micro, pequenos e médios empreendedores já despertaram para as novas pressões de mercado que orientam a tomada de decisão de grandes empresas nacionais e internacionais, como a sustentabilidade?

\section{SUSTENTABILIDADE NAS ORGA- NIZAÇÕES}

O conceito de sustentabilidade vem sendo incorporado e praticado lentamente por lideranças empresariais, governamentais e pela sociedade civil. Entretanto, as tensões crescem e demandam reações urgentes, que ultrapassem o nível de discurso e declaração de princípios (ALMEIDA, 2007).

Para Barbieri e Cajazeira (2009), o movimento do desenvolvimento sustentável só alcançará seus objetivos se for globalizado e contar com a participação ativa de governos, empresas 
e sociedade civil. Os autores destacam o papel central das empresas neste processo, já que muitos problemas socioambientais foram produzidos ou estimulados por suas atividades.

Almeida (2007) considera o setor privado o maior responsável pelo rumo que a humanidade tomará, uma vez que a maior fatia do poder no mundo moderno está concentrada nos empreendimentos empresariais e somente eles têm a disciplina e os recursos necessários para liderar uma transformação nos padrões de desenvolvimento com a urgência requerida.

Barbieri e Cajazeira (2009) afirmam que a contribuição das organizações ao desenvolvimento sustentável está centrada em três dimensões: a econômica, a social e a ambiental. Não há um abandono das demais dimensões da sustentabilidade, mas uma concentração no que é específico à atuação das organizações. Os autores concluem que uma organização sustentável é aquela que orienta suas atividades pelas dimensões da sustentabilidade que lhe são específicas e busca alcançar seus objetivos atendendo, simultaneamente, a equidade social, a prudência ecológica e a eficiência econômica.

Barbieri e Cajazeira (2009, p. 70) utilizam o termo empresa sustentável para definir a empresa que "procura incorporar os conceitos e objetivos relacionados com o desenvolvimento sustentável em suas políticas e práticas de modo consistente". A incorporação desses objetivos, para a empresa, significa adotar estratégias de negócios e atividades que atendam suas necessidades e as de seus stakeholders; protegendo, sustentando e aumentando os recursos humanos e naturais fundamentais para o futuro (BARBIERI; CAJAZEIRA, 2009).

Almeida (2007) afirma que a perda do capital ambiental vai modificar as condições em que as empresas operam; assim, surgirão novas oportunidades de negócios a partir do desenvolvimento e da adoção de mecanismos e métodos mais eficientes para usar o capital ambiental. Portanto, entende-se que empresas sustentáveis tendem a ser mais criativas para aproveitar as novas oportunidades, destacando-se no mercado.
Mahler (2007) avaliou as práticas de sustentabilidade em indústrias de diversos setores e tamanhos nos Estados Unidos e concluíram que $60 \%$ das empresas pesquisadas já adotam práticas sustentáveis. Suas principais motivações são o fortalecimento da marca e a diferenciação dos produtos. Os autores concluem que muitas empresas veem na sustentabilidade uma poderosa fonte de vantagem competitiva, percebendo que melhorias em direção à sustentabilidade diminuem custos, criam novos produtos e demanda, evitam problemas em longo prazo e são um diferencial sobre os concorrentes.

Esty e Winston (2006) atentam que as pequenas empresas não estão livres desta "Onda Verde" e devem adequar-se a ela por cinco razões:

a) a legislação ambiental que só se aplicava às grandes empresas, agora abrange as empresas menores;

b) pequenas empresas também estão na mira de grupos ativistas, que exigem a diminuição de seus impactos ambientais;

c) a redução dos custos permite maior acessibilidade a sistemas de monitoramento de poluição e de verificação de conformidade regulamentar;

d) são pressionadas para adequar-se às normas ambientais quando atuam como fornecedoras de grandes companhias certificadas por sistemas de gestão ambiental;

e) são mais ágeis do que concorrentes maiores para responder às mudanças macroambientais, levando vantagem e identificando nichos de mercado.

Há uma busca por normas socioambientais que permitam avaliar práticas empresarias, possibilitando o reconhecimento e validação por meio de auditorias por entidades independentes especializas. Essas normas procuram garantir uma padronização nas diretrizes que são buscadas para definir uma gestão sustentável reconhecida (OLIVEIRA, 2002; LEIPZIGER, 2003). Utilizando-se de metodologia análoga à das normas da série ISO, a SA 8000, por exemplo, é 
uma dessas normas socioambientais que garante uma credibilidade e acessibilidade já mundialmente conhecidas. Oliveira (2002, p. 17) afirma que "a norma foi elaborada baseando-se no bem-sucedido modelo das normas da série ISO 9000, utilizando-se os princípios da ação corretiva e preventiva, da melhoria contínua, das auditorias (internas e externas) e no sistema de gestão baseado na documentação". Outras normas também apresentam este enfoque socioambiental que podem ser comparadas entre si, perante critérios de processo produtivo, relações com a comunidade, relações com os empregados e seus dependentes e integração dos sistemas de gestão (OLIVEIRA et al., 2007).

\section{EMPREENDEDORISMO SUSTEN- TÁVEL}

As discussões mundiais sobre desenvolvimento sustentável tornaram-no um objetivo social e uma prioridade para as políticas públicas. Considerando a capacidade do empreendedorismo de contribuir para o alcance dos objetivos das políticas públicas, como crescimento econômico, geração de emprego e renda e inovação tecnológica; a partir daí, surgiu o questionamento acerca do papel que o empreendedorismo pode assumir para contribuir com o desenvolvimento sustentável (PARRISH, 2010).

O termo Sustainable Entrepreneurship (empreendedorismo sustentável) vem sendo aplicado a empreendedores que integram propósitos ambientais e sociais no mesmo empreendimento, orientados por diferentes motivos e valores (PARRISH, 2010). Desse modo, um empreendimento sustentável é capaz de realizar suas atividades e contribuir com o desenvolvimento sustentável do macro sistema social e ambiental do qual faz parte (BOSZCZOWSKI; TEIXEIRA, 2012; PARRISH, 2010).

Young e Tilley $(2006$, p. 1) complementam definindo empreendedorismo sustentável como "a organização que tem a sustentabilidade no centro de sua estrutura, operações e gestão: em essência, uma organização que vai além do exigido para demonstrar eficiência no seu caminho para ser sustentável".

Além disso, Parrish (2010) identifica duas abordagens a respeito das razões que motivam empreendedores a aderir à sustentabilidade. A primeira e mais usual considera que os empreendedores são, por definição, motivados pelo lucro. Logo, eles estão interessados em contribuir com o desenvolvimento sustentável quando isto lhes proporciona ganhos financeiros. Nesta perspectiva, reduzir o impacto ambiental e engajar-se em iniciativas de responsabilidade social empresarial tem o objetivo de gerar vantagem competitiva.

A segunda abordagem foi desenvolvida a partir da observação dos diversos motivos e valores que impulsionam os empreendedores para a sustentabilidade. Parrish (2010) verificou a existência de empresas cujo propósito primordial é contribuir com a melhoria do bem-estar social e ambiental e que consideram a receita proveniente de suas atividades um meio para atingir esse propósito.

Young e Tilley (2006) analisam dois modelos de empreendedorismo sustentável, desenvolvidos por Dyllick e Hockerts e por McDonough e Braungart, e concluem que nenhum deles integra os objetivos social, ambiental e econômico simultaneamente sob o propósito único da sustentabilidade.

Assim, os autores propõem um novo modelo (Figura 1) a partir dos dois modelos analisados, no qual empreendedorismo sustentável é o resultado da integração sistêmica das dimensões econômica, social e ambiental do empreendedorismo. Ou seja, um empreendimento é sustentável quando é ambientalmente sustentável, socialmente sustentável, economicamente sustentável e apresentar as doze variáveis de relacionamento operando em conjunto. Segundo os autores, este modelo permite identificar fases do empreendedorismo sustentável e as práticas de gestão adotadas. 


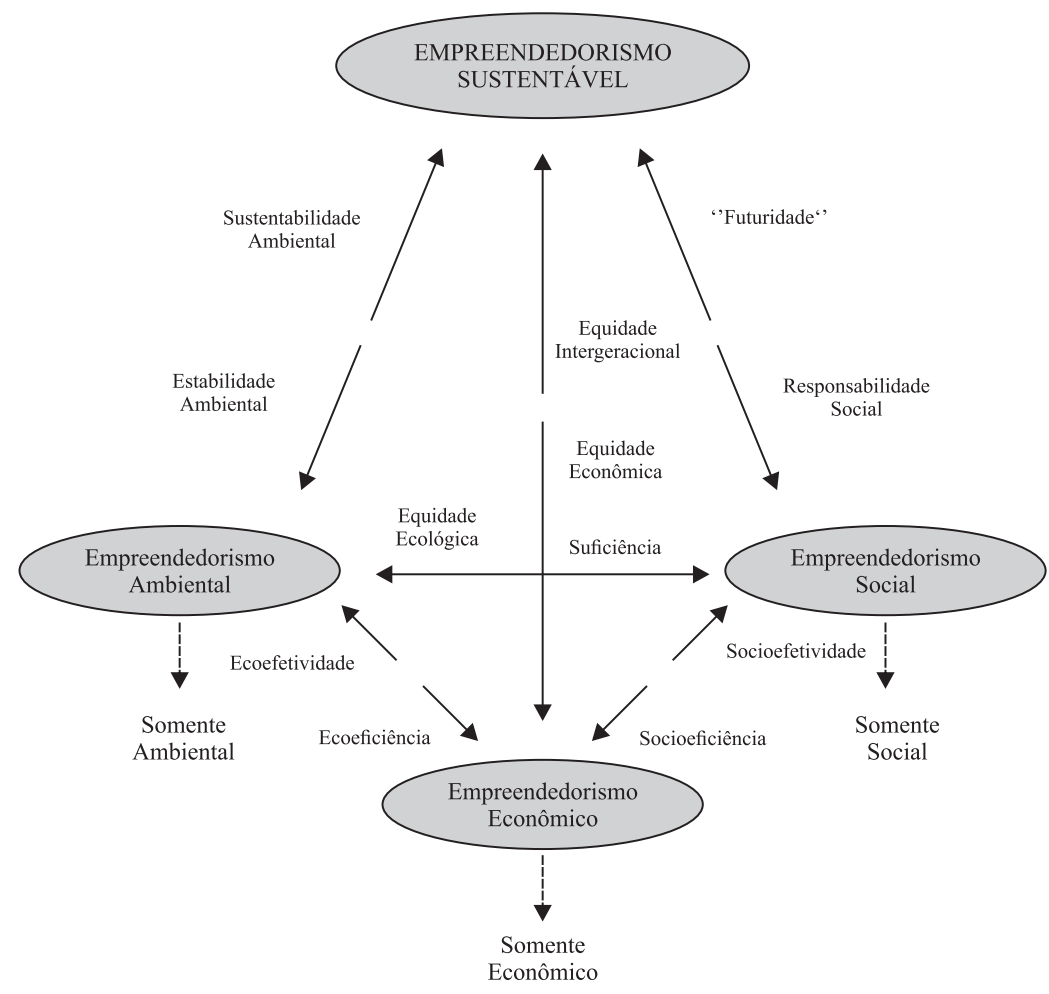

Figura 1 - Modelo de empreendedorismo sustentável Fonte: adaptado de Young e Tilley (2006, p. 410).

Young e Tilley (2006) explicam as variáveis de relacionamento do modelo. Quanto ao relacionamento entre empreendedorismo econômico e empreendedorismo ambiental, há as variáveis:

a) ecoeficiência - adoção de soluções do tipo ganha-ganha, buscando crescimento econômico e proteção ambiental simultaneamente;

b) ecoefetividade - adoção de soluções empresariais que dão sustentação à vida e são restauradoras e regenerativas, além de eficientes.

No que trata do relacionamento entre empreendedorismo econômico e empreendedorismo social, os autores apresentam como variáveis:

a) socioeficiência - adoção de soluções do tipo ganha-ganha, buscando crescimento econômico e proteção social simultaneamente;

b) socioefetividade - as organizações atuam como agentes de mudança so- cial, tendo uma missão social de gerar impactos positivos e sustentáveis na sociedade.

Quanto ao relacionamento entre empreendedorismo social e empreendedorismo ambiental, os autores abordam as variáveis:

a) equidade ecológica- todas as pessoas têm direito aos recursos ambientais;

b) suficiência - as empresas têm a responsabilidade de canalizar a demanda para o consumo sustentável (procura por produtos sustentáveis).

No que se refere ao relacionamento entre empreendedorismo econômico e empreendedorismo sustentável, tem-se as variáveis:

a) equidade econômica - justa distribuição da riqueza entre as gerações presentes e as futuras;

b) equidade intergeracional - a prosperidade econômica das futuras gerações deve ser considerada nas decisões e operações empresariais. 
O relacionamento entre empreendedorismo ambiental e empreendedorismo sustentável envolve as variáveis:

a) estabilidade ambiental - esforço para alcançar a estabilidade ambiental e, onde necessário, restaurar os diversos ecossistemas;

b) sustentabilidade ambiental - considerar a sustentabilidade do meio ambiente em longo prazo nas decisões e operações empresariais.

Finalmente, o relacionamento entre empreendedorismo social e empreendedorismo sustentável envolve as variáveis:

a) responsabilidade social - empresas e indivíduos assumem responsabilidade pelos impactos positivos e negativos, diretos e indiretos sobre as gerações presentes;

b) "futuridade" - considerar o bem-estar social das gerações futuras nas decisões e operações empresariais.

Young e Tilley (2006) reconhecem que seu modelo é bastante complexo e que ainda precisa ser testado em pesquisas mais amplas para verificar se é possível um empreendimento ser verdadeiramente sustentável dentro das restrições estruturais da economia liberal.

Portanto, para o presente trabalho, adota-se o pressuposto de que empreendedorismo sustentável é um conceito recente e seus parâmetros ainda estão em definição, mas é possível observar a intenção de estruturá-lo sobre três dimensões: empreendedorismo econômico, empreendedorismo social e empreendedorismo ecológico (DALMORO, 2009). O autor entende cada dimensão como:

a) dimensão do Empreendedorismo econômico - baseada na concepção clássica de empreender com o objetivo de desenvolver uma atividade que gere lucro. A criação de valor está voltada para o mercado. A sustentabilidade refere-se à capacidade da empresa de manter-se viva, de ser um negócio autossustentável; b) dimensão do Empreendedorismo Social - baseada nas contribuições dos empreendedores para o bem-estar de todos os membros da sociedade. As atividades dos empreendedores criam valores sociais e culturais; logo, empreendedorismo social é definido como o empreendimento que objetiva gerar valores sociais de maneira criativa e inovadora;

c) dimensão do Empreendedorismo Ecológico - baseada na crescente preocupação com as causas ambientais. Há criação de valor no âmbito ecológico. Um empreendimento ecológico utiliza estratégias de negócio proativas e ecologicamente orientadas, redefinindo sua cultura e suas relações sociais.

\section{METODOLOGIA}

O presente trabalho consiste em um estudo multicaso, do tipo exploratório e descritivo. Quanto aos procedimentos técnicos utilizados para a coleta de dados, realizaram-se pesquisa bibliográfica e entrevistas. Na fase exploratória, recorreu-se à pesquisa bibliográfica, um estudo baseado em material já elaborado, principalmente livros e artigos científicos, cuja principal vantagem é permitir ao investigador abordar uma gama de fenômenos mais ampla do que conseguiria por meio de pesquisas diretas (GIL, 2006). Para esta etapa, realizou-se leitura crítica e reflexiva de livros, periódicos científicos, dissertações, anais de encontros acadêmicos e revistas de negócios relacionados ao problema investigado.

A fase descritiva da pesquisa teve o objetivo de levantar opiniões, atitudes e crenças dos empreendedores quanto à Sustentabilidade Empresarial. Para isso, foram realizadas entrevistas parcialmente estruturadas que envolvem duas pessoas em situação "face a face", na qual uma formula questões a partir de uma relação de pontos previamente definida e a outra responde (GIL, 2006).

O roteiro de entrevista utilizado foi elaborado pelos autores e está baseado nos crité- 
rios das dimensões da sustentabilidade empresarial propostos por Dalmoro (2009) e Mahler (2007). Utilizou-se ainda a Lista de Verificação para Auditoria da SA 8000 desenvolvida por Oliveira (2002) para melhor definir os critérios relacionados à dimensão social da sustentabilidade empresarial. SA 8000 é uma certificação internacional criada para verificar as condições de trabalho nas organizações, seguindo o modelo da ISO 9001 (certificação da qualidade); por meio da SA 8000 é implantado um Sistema de Gestão da Responsabilidade Social nas organizações (OLIVEIRA, 2002).

O roteiro de entrevista foi estruturado sobre quatro construtos, para cada um dos quais foram desenvolvidos quatro questionamentos. Procurou-se, assim, abordar uniformemente os construtos para atender aos objetivos da pesquisa. Os construtos são os seguintes:

a) compreensão do empreendedor a respeito de sustentabilidade empresarial;

b) presença da dimensão econômica da sustentabilidade empresarial na organização;

c) presença da dimensão ambiental da sustentabilidade empresarial na organização;

d) presença da dimensão social da sustentabilidade empresarial na organização.

O Parque Tecnológico do NUTEC (PARTEC) foi definido como o campo empírico da pesquisa, pois se acredita que uma incubadora de empresas é um ambiente propício para encontrar empreendedores mais abertos e interessados em adequar-se às mudanças macroambientais. Esta ideia se aplica ao PARTEC, que procura contribuir com a inserção de micro, pequenas e médias empresas no mercado de negócios de alto valor agregado, sustentáveis e de sucesso duradouro (NUTEC, 2009).

Foram entrevistados três dos quatro empreendedores responsáveis pelas quatro empresas incubadas no PARTEC no segundo semestre de 2014, período em que foi desenvolvida a pesquisa. As entrevistas foram realizadas nos dias 14, 16 e 20 de outubro, com duração média de uma hora.
O PARTEC tem a missão de "apoiar a geração e consolidação de empresas de base tecnológica, visando o desenvolvimento de novos produtos/processos e caracterizando-se como a 'expansão do conhecimento tecnológico"” (NUTEC, 2009). Entretanto, recentemente, a organização optou por abrigar empresas de base tecnológica ou tradicional, sendo uma incubadora mista.

A incubadora do NUTEC atende empresas localizadas na Região Metropolitana de Fortaleza, cujos produtos, processos ou serviços contribuem com a inovação. Há duas formas de incubação: a residente, quando o escritório da empresa está localizado no PARTEC; e a virtual (à distância), quando o empresário mantém o escritório da empresa fora da incubadora (NUTEC, 2009).

Para analisar os dados levantados nas entrevistas, optou-se pela técnica de análise de conteúdo. De acordo com Laville e Dionne (2008, p. 214), esta técnica "consiste em desmontar a estrutura e os elementos desse conteúdo para esclarecer suas diferentes características e extrair sua significação".

\section{ANÁLISE DOS RESULTADOS}

Os dados obtidos nas entrevistas foram agrupados de acordo com seis temas: identificação das empresas; identificação das soluções oferecidas; compreensão de sustentabilidade empresarial; presença da dimensão econômica da sustentabilidade empresarial; presença da dimensão ambiental da sustentabilidade empresarial; e presença da dimensão social da sustentabilidade empresarial. Dentro dessas áreas temáticas, os dados fornecidos pelos três entrevistados são apresentados e, em seguida, analisados.

\subsection{IDENTIFICAÇÃO DAS EMPRESAS}

A empresa A é uma micro empresa agroindustrial produtora de caju, cajuína e corante amarelo natural. Foi fundada em novembro de 2005 e começou a comercializar seus produtos em 2008. Está incubada para desen- 
volver o corante amarelo natural e um processo produtivo mais eficiente para a cajuína.

A empresa B é uma micro empresa industrial que desenvolve e oferta equipamentos para desidratar frutas e hortaliças, podendo ser adaptado para derivados de origem animal. Fundada em 2010, ainda está na fase de desenvolvimento dos equipamentos (os protótipos estão prontos e em fase de teste) e prevê o início da comercialização dos produtos em fevereiro de 2015.

A empresa $\mathrm{C}$ também é uma micro empresa e atua nos setores industrial e prestação de serviços. Foi fundada em 1985, pelo pai do atual empreendedor, mas ficou parada por 15 anos. $\mathrm{O}$ atual empreendedor retomou as atividades da empresa em 2005. Atualmente, a empresa produz e comercializa água desmineralizada para baterias e radiadores, e realiza serviços de consultoria e pesquisa na área de análise e aproveitamento de resíduos de processos industriais. Também está desenvolvendo dois processos para aproveitamento da glicerina gerada na produção de biodiesel. Estes produtos estão em fase de construção dos protótipos para realização de testes. O empreendedor pensa em vender ou licenciar os processos, mas se interessa em montar uma unidade beneficiadora de glicerina caso ocorra um aporte de recursos na empresa.

$\mathrm{O}$ fato de a empresa $\mathrm{B}$ ainda não estar produzindo e a empresa $\mathrm{C}$ também está em fase de desenvolvimento de seus principais produtos limitou a análise das atividades empresariais. Por esse motivo, procede-se à análise das soluções oferecidas pelos três negócios sob a ótica da sustentabilidade, como uma tentativa de compensar esta limitação.

\subsection{IDENTIFICAÇÃO DAS SOLUÇÕES OFERECIDAS}

A empresa A oferece soluções para o aproveitamento do pedúnculo do caju; um resíduo da produção de castanha, que representa $90 \%$ do peso do caju e aproximadamente $88 \%$ de sua produção nacional é subaproveitado ou desperdiçado. A empresa fabrica cajuína (uma bebida bastante rica em vitaminas, com alto va- lor nutricional e não contém conservantes, açúcares, adoçante ou água) e Carotenoide Amarelo de Caju (corante natural amarelo para alimentos). Assim, contribui para o aproveitamento do resíduo oferecendo alimentos mais saudáveis.

O negócio da empresa $\mathrm{B}$ é disponibilizar soluções adequadas em desidratação para pequenos produtores agrícolas, oferecendo estufas com alta eficiência energética que utilizam fontes de energia renováveis, como a energia solar e a de biomassa. Desse modo, a empresa viabiliza o uso de resíduos provenientes das culturas agrícolas e do beneficiamento dos gêneros agrícolas como fonte de energia para a desidratação. Como exemplo, temos o uso da casca e do pseudocaule da banana na desidratação desta fruta.

Outros benefícios do produto são: disponibilizar frutas e hortaliças sazonais durante todo o ano; evitar a queda do preço ou o desperdício dos produtos durante os picos de produção; permitir agregar valor às frutas e hortaliças; gerar economias de transporte com a diminuição do tamanho e do peso dos produtos desidratados; fixar o homem no campo e aumentar a renda dos agricultores.

O produto vem atender a uma necessidade do mercado, pois as estufas disponíveis no país têm capacidade produtiva limitada, baixa eficiência térmica e alto custo operacional devido ao uso de energia elétrica ou gás liquefeito de petróleo (GLP). Por isso, produtos desidratados têm preço elevado e baixo consumo no Brasil.

A empresa $\mathrm{C}$ se dedica a oferecer soluções para resíduos gerados em processos produtivos industriais. A glicerina de alto grau de impureza é um resíduo da produção de biodiesel que não pode ser lançado no meio ambiente. Atualmente, as indústrias de biodiesel estão estocando este resíduo ou pagando para alguém armazená-lo e já precisaram parar a produção por não ter onde guardar a glicerina. Assim, a empresa oferecerá um processo de purificação que tornará a glicerina atrativa para a indústria química e um processo que viabilizará seu uso como fonte de energia em motores de combustão.

A análise das soluções oferecidas permite classificar estes empreendimentos como 
empreendedorismo por oportunidade, pois os empreendedores perceberam oportunidades de negócio no mercado e criaram suas empresas com planejamento e objetivos claros (DORNELAS, 2008). Isto corrobora as afirmações de Hisrich e Peters (2004) sobre a importância das pequenas empresas para a inovação e o papel do empreendedorismo para conectar novas tecnologias ao mercado.

Considerando o conceito de efetividade em sustentabilidade de Young e Tilley (2006), é possível afirmar que estas empresas são ecoefetivas; pois ofertam soluções que dão sustentação à vida, são restauradoras, regenerativas e eficientes. Assim, suas soluções permitem a sobrevivência das organizações e da natureza. Também podem ser consideradas socioefetivas, porque geram impactos positivos e sustentáveis na sociedade através de seus produtos. Por favorecer a empresa, a natureza e a sociedade simultaneamente, pode-se afirmar que as soluções oferecidas pelas empresas são sustentáveis.

\subsection{COMPREENSÃO DE SUSTENTA- BILIDADE EMPRESARIAL}

O empreendedor da empresa A acredita que sustentabilidade significa produzir mais do que é gasto na atividade empresarial, nos sentidos econômico e ambiental. Por outro lado, compreende empresa sustentável como aquela que se mantém em longo prazo, com faturamento suficiente para cobrir seus gastos, satisfazendo às necessidades de seus funcionários e da sociedade em que a empresa está inserida, e respeitando o meio ambiente.

O empreendedor da empresa B entende sustentabilidade como o desenvolvimento de atividades com recursos renováveis, usando tecnologia de alta eficiência que garanta a competitividade no mercado. Assim, de acordo com ele, uma empresa sustentável utiliza recursos renováveis e tecnologia de alta eficiência, garantindo competitividade no mercado e respeitando o meio ambiente.

Já o empreendedor da empresa $\mathrm{C}$ define sustentabilidade como a capacidade de "dar sustento" para a manutenção de algo. Portanto, uma empresa sustentável é capaz de gerar o "sustento financeiro" necessário para se manter em funcionamento.

Perceberam-se dificuldades para conceituar sustentabilidade, corroborando Van Bellen (2007) quando afirma que as diversas abordagens e definições de sustentabilidade dificultam sua compreensão. Além disso, os empreendedores demonstraram percepções restritas às dimensões econômica, ambiental e/ou social o que fortalece a ideia de Barbieri e Cajazeira (2009) sobre a atuação das organizações (em prol da sustentabilidade) estar centrada nas dimensões que lhes são específicas (econômica, social e ambiental).

Quanto à compreensão de sustentabilidade empresarial, observa-se que apenas o empreendedor da empresa A considerou a presença simultânea das três dimensões da sustentabilidade empresarial; enquanto o empreendedor da empresa $\mathrm{B}$ considerou as dimensões econômica e ambiental e o empreendedor da empresa $\mathrm{C}$ limitou-se à econômica.

$\mathrm{O}$ fato de todos terem considerado a dimensão econômica está de acordo com a ideia apresentada por Hisrich e Peters (2004, p. 29): o empreendedor se dedica e assume riscos em suas atividades porque espera receber como recompensa "satisfação e independência econômica e pessoal". Já o fato de a dimensão ambiental ser considerada por dois deles, enquanto que a social por apenas um, permite concluir que os empresários estão mais susceptíveis à degradação ambiental do que às causas sociais, possivelmente devido às frequentes discussões acerca da situação ambiental.

\subsection{PRESENÇA DA DIMENSÃO ECO- NÔMICA DA SUSTENTABILIDA- DE EMPRESARIAL}

Nesta área temática, são abordadas as atividades da empresa que atendem a suas necessidades e às de seus stakeholders, com o objetivo de analisar a eficiência econômica e a capacidade de manutenção da empresa. 
A empresa A conseguiu atingir seu ponto de equilíbrio após três anos de operação, mas ainda não gera o retorno financeiro suficiente para realizar todos os reinvestimentos necessários para o crescimento da empresa. O empreendedor verifica uma expansão do seu mercado potencial, devido às preocupações emergentes com a saúde, a alimentação e a sustentabilidade. Toda a produção é vendida sem grandes esforços de divulgação, mas a empresa não consegue atender completamente à demanda pelo produto, devido às limitações tecnológicas no processo produtivo.

A tecnologia utilizada na produção de cajuína é artesanal e foi desenvolvida no século XVIII; por isso, não permite produzir em larga escala. O empreendedor está investindo no desenvolvimento de uma nova tecnologia, que tornará o processo produtivo mais eficiente e econômico e aumentará a qualidade do produto. Além disso, houve uma redução dos custos de embalagem com a utilização da garrafa de vidro reciclado.

O empreendedor identifica como um dos principais riscos do negócio a contaminação do produto (que é um alimento); a falta de capacidade produtiva para atender aos pedidos de clientes; e a concorrência por preço, que impera no mercado de cajuína. Para gerenciar esses riscos, investe na inovação do processo produtivo e na diferenciação do produto, desenvolvendo cajuína de melhor qualidade e uma linha orgânica.

Há geração de novos postos de trabalho, pois a empresa conta com sete funcionários fixos e contrata 13 temporários no período de safra do caju.

A empresa B ainda não comercializa seus produtos, mantendo suas atividades através de recursos recebidos do Banco do Nordeste (BNB) - para o custeio das pesquisas e do Conselho Nacional de Desenvolvimento Científico e Tecnológico (CNPq) - para bolsas de pesquisa e de iniciação científica. O empreendedor também fez um aporte inicial de capital e aguarda a liberação de recursos da Financiadora de Estudos e Projetos (FINEP) - para aperfeiçoar o sistema atual, desenvolvendo um segundo sistema mais eficiente.
A empresa realiza investimentos em pesquisa e desenvolvimento: lançará a primeira linha de produtos em 2015 e já planeja um segundo sistema mais eficiente a ser lançado em 2018 para evitar perda de participação de mercado.

O empreendedor afirma que há um amplo mercado potencial para o produto e que já existem 30 interessados aguardando o lançamento. A empresa procura ter custos reduzidos para garantir preço acessível. Parte do processo produtivo é terceirizada, a empresa realiza apenas as operações fins e desenvolveu um produto mais compacto e com processos mais simples que o da concorrência, gastando menos insumos e necessitando de menor capacidade produtiva.

O empreendedor identifica como principais riscos do negócio a imitação do produto por concorrentes e o desenvolvimento de tecnologia mais eficiente. Para gerenciar esses riscos, registrou o processo de secagem no Instituto Nacional de Propriedade Industrial (INPI), sendo ele o detentor da patente, e desenvolve um planejamento estratégico para a empresa com o apoio do SEBRAE e do PARTEC. Com esse apoio, também realizou estudos de viabilidade e de preço do produto.

A empresa ainda não gera novos postos de trabalho, mas contratará funcionários quando começar a produzir para o mercado.

A empresa $\mathrm{C}$ se mantém com a receita obtida pela comercialização de água desmineralizada e com a realização dos serviços, além de contar com recursos de órgãos financiadores de pesquisas. Esses valores não são suficientes para expandir a empresa, apenas para mantê-la viva e suportar os investimentos em pesquisa e desenvolvimento. O estudo de viabilidade realizado pelo empreendedor indica que, com a comercialização dos processos de aproveitamento da glicerina, o negócio gerará o retorno necessário para se manter.

O mercado potencial de seus produtos foi expandido com a inauguração da usina de biodiesel da Petrobrás em Quixadá - CE, em agosto de 2008, e com a pressão governamental e social sobre as empresas para a correta destinação de resíduos industriais. A prestação de 
serviços, por exemplo, surgiu a partir de um pedido de empresários.

A produção de água desmineralizada não envolve muitos custos, assim como a prestação de serviços. Os custos dos novos produtos ainda estão sendo calculados. $\mathrm{O}$ empreendedor identifica como principais riscos a entrada de novos competidores no mercado e a rápida inovação tecnológica. Para gerenciar estes riscos, deu entrada no pedido de patente para os dois processos no INPI.

Atualmente, a empresa gera dois postos de trabalho na desmineralização de água e quatro bolsas de pesquisa no desenvolvimento dos processos e prestação de serviços.

Todas as empresas demonstraram faturamento insuficiente para sobreviver em longo prazo; por isso, conclui-se que não são economicamente sustentáveis. Entretanto, esta pode ser uma situação momentânea, considerando que:

a) são empresas novas e/ou em fase de desenvolvimento de produtos;

b) há demanda crescente pelas soluções que oferecem;

c) estão cientes dos riscos que correm e agem para superá-los.

\subsection{PRESENÇA DA DIMENSÃO AM- BIENTAL DA SUSTENTABILIDA- DE EMPRESARIAL}

Nesta área temática, são abordadas as atividades da empresa dedicadas à proteção, à sustentação e ao aumento dos recursos naturais fundamentais para o futuro. Há o objetivo de analisar a prudência ecológica das empresas.

A empresa A comprará uma nova caldeia que permitirá reduzir a $1 / 7$ o consumo de energia na produção em dezembro de 2014, quando prevê a liberação dos recursos concedidos pelo BNB.

Esta empresa procura otimizar o uso de recursos, aproveitando o bagaço de caju como adubo no pomar e usando as duas faces do papel no escritório. Quanto às embalagens, a garrafa da cajuína é de vidro reciclado, mas a embalagem das garrafas deixou de ser de papelão e passou a ser de plástico devido aos custos.
A empresa tem uma estação de tratamento de efluentes para tratar a água usada na lavagem do caju e das garrafas antes de devolvê-la ao meio ambiente. Há ainda um plano de gerenciamento de resíduos sólidos: os cacos de vidro são vendidos para a Companhia Industrial de Vidros (CIVI), que recicla o material; os rótulos de papel são depositados em aterro sanitário; as cinzas da lenha, utilizada como fonte de energia na produção, são colocadas no campo. A fábrica ainda não tem filtros, mas o problema será solucionado com a aquisição da nova caldeira, que virá com filtros.

A análise da empresa $\mathrm{B}$ foi limitada por ainda não existir processo produtivo. No escritório, o empreendedor preocupa-se em economizar energia (desligar os aparelhos de ar condicionado, os monitores de computador e lâmpadas quando não estão em uso) e usa papel reciclado, aproveitando ambas as faces. Vale ressaltar que o papel é fornecido pelo NUTEC, que decide a compra do produto reciclado.

Quando se se analisa o produto da empresa, observa-se que a solução oferecida evita o desperdício de alimento e a consequente geração de resíduos. O produto utiliza energia renovável, aproveitando resíduos da produção na geração de energia. Usa garrafa pet como matéria-prima, atuando como isolante térmico em sistemas de estocagem de fluxo interno e substitui vidro ou polietileno no sistema de geração de energia solar. Além disso, o equipamento tem um sistema de reaproveitamento de calor, operando com menor quantidade de energia.

$\mathrm{O}$ empreendedor da empresa $\mathrm{C}$ usa papel reciclado no escritório (também fornecido pelo NUTEC), mas não se preocupa em aproveitar as duas faces. Ele procura economizar energia no escritório, desligando aparelhos de ar condicionado, os monitores de computador e lâmpadas quando não estão em uso. Mas nunca pensou sobre isso no processo produtivo de seus produtos. Quanto às embalagens, utiliza garrafas de plástico reciclado para a água desmineralizada e reutiliza as garras devolvidas por um de seus clientes, que é certificado por normas ambientais. 
É possível considerar a empresa A ambientalmente sustentável; porque procura reduzir o consumo de energia, otimizar o uso de recursos por meio de reciclagem e reutilização, e gerenciar os resíduos gerados pela empresa.

Quanto à empresa B, qualquer conclusão seria precipitada, porque ainda não está em operação. Entretanto, é possível considerar seu produto ambientalmente sustentável.

Os produtos da empresa $\mathrm{C}$ também podem ser considerados ambientalmente sustentáveis, porém, o empreendedor demonstrou poucas atitudes orientadas pela prudência ecologia e isso o levou a considerar a empresa ambientalmente insustentável.

\subsection{PRESENÇA DA DIMENSÃO SO- CIAL NA SUSTENTABILIDADE EMPRESARIAL}

Nesta área temática, são abordadas as atividades da empresa dedicadas à proteção, à sustentação e ao aumento dos recursos humanos. Há o objetivo de analisar a equidade social das empresas.

A empresa $\mathrm{A}$ atende às exigências legais: paga pelas horas extras e os contratos de trabalho de empregados fixos e temporários são formalizados. De acordo com o empreendedor, as condições de trabalho são adequadas, os horários de trabalho são respeitados e todos os empregados são tratados de forma digna e igualitária. Entretanto, não há benefícios além daqueles determinados por lei.

A empresa não desenvolve atividades para beneficiar a comunidade em que está inserida devido à limitação de recursos que enfrenta, mas o empreendedor acredita que o fato de estar gerando emprego na zona rural do município de São Gonçalo do Amarante já é um benefício para a comunidade local, que antes não tinha emprego fixo ou carteira assinada.

$\mathrm{O}$ produto oferecido não traz efeitos negativos para a sociedade; pelo contrário, é saudável e rico em vitaminas. Inclusive, há uma linha orgânica de cajuína.

A empresa B não tem empregados, seus colaborados são bolsistas pagos pelo CNPq. Além da bolsa, os colaboradores não recebem qualquer outro tipo de benefício. As condições de trabalho são adequadas, os horários de trabalho respeitados e os bolsistas tratados de forma digna e igualitária. A empresa não interage com a comunidade em que está inserida.

O produto oferecido não é prejudicial à sociedade, gera vários benefícios: desde a fixação do homem no campo até a oferta de alimentos ricos em vitaminas e minerais com prazo de validade mais amplo.

A empresa $C$ não assina a carteira de trabalho de seus dois empregados. Os outros quatro colaboradores recebem bolsas do $\mathrm{CNPq}$ e, quando realizam consultoria, são pagos como autônomos. Não há outros benefícios. As condições de trabalho são adequadas, os horários são respeitados e todos são tratados de forma digna e igualitária. A empresa não atua na comunidade em que está inserida. O produto oferecido não produz efeito negativo para a sociedade, podendo ser considerado positivo se analisada a importância do meio ambiente para a vida humana.

Verificou-se que nenhuma das empresas pode ser considerada socialmente sustentável, pois os empreendedores:

a) oferecem o mínimo aceitável aos funcionários, nem sempre respeitando seus direitos legais;

b) não percebem a importância do empreendedorismo para a geração de bem estar social;

c) não se esforçam para reter o capital humano em suas empresas.

Sobre o último ponto, os empresários B e C citaram a perda de importantes colaboradores que receberam propostas de salário e benefícios mais interessantes de outras empresas. Por outro lado, os produtos oferecidos pelas três empresas são positivos para a sociedade.

Por fim, identifica-se que nenhuma das três empresas pode ser considerada como sustentável, porque não atendem simultaneamente à sustentabilidade econômica, social e ambiental. Acaba-se obtendo um resultado semelhan- 
te ao observado por Brito, Brunstein e Amaro (2014) ao observar que a sustentabilidade é mais observada na elaboração de produtos com baixo impacto socioambiental. Por outro lado, a questão da sustentabilidade não é uma das principais preocupações dos empreendedores ou mesmo objeto de atenção a curto e médio prazo. As implicações não ficam restritas apenas à manutenção do negócio, mas fazem com procedimentos errôneos continuem sendo reproduzidos no mercado.

\section{CONSIDERAÇÕES FINAIS}

A partir da compreensão que o empreendedorismo sustentável é um conceito recente e ainda em definição, sendo estruturado sobre três dimensões: empreendedorismo econômico, empreendedorismo social e empreendedorismo ecológico, esta pesquisa ganhou relevância ao analisar a implementação da sustentabilidade empresarial nos empreendimentos atendidos pelo PARTEC, permitindo verificar que essas empresas não atendem plenamente aos quesitos observados com relação as três dimensões de sustentabilidade.

Perceberam-se dificuldades na compreensão do conceito de sustentabilidade e, consequentemente, de sustentabilidade empresarial. Apenas um empreendedor considerou a presença simultânea das três dimensões da sustentabilidade empresarial em sua definição. Com relação aos dois empreendedores restantes, um considerou as dimensões econômica e ambiental e o outro se limitou à econômica.

Quanto à implementação das dimensões da sustentabilidade empresarial, as empresas podem classificadas como economicamente insustentáveis, pois obtêm faturamento insuficiente para a manutenção das operações no longo prazo. Estas organizações também foram apontadas como socialmente insustentáveis, dado que os empreendedores oferecem o mínimo aceitável aos funcionários, em alguns casos, chegam a cometer infrações que podem ser interpretadas como desrespeitos as legislações trabalhistas; não se esforçam para reter o capi- tal humano em suas empresas; e não interagem com a comunidade em que estão inseridos.

Uma das empresas foi considerada ambientalmente sustentável. Algumas ações justificam esta classificação como: a redução do consumo de energia, a otimização do uso de recursos através de reciclagem e reutilização, e o gerenciamento dos resíduos gerados pela empresa. Por outro lado, deixou-se de avaliar as outras duas empresas. Elas ainda estão em fase de desenvolvimento de produtos e, portanto, qualquer conclusão seria precipitada.

Desse modo, as organizações não podem ser consideradas plenamente sustentáveis. Entretanto, pode-se afirmar que as soluções oferecidas por elas são sustentáveis, pois permitem a sobrevivência das organizações e da natureza, além de gerar impactos positivos e sustentáveis na sociedade. A análise das soluções oferecidas permite, ainda, classificar estes empreendimentos como empreendedorismo por oportunidade. Observou-se ainda que os empreendedores demonstraram, por meio de suas atitudes, maior preocupação com a dimensão ambiental do que com a social.

Esta pesquisa conseguiu atingir os objetivos propostos, referentes à análise da implementação da sustentabilidade empresarial, da compreensão dos empreendedores sobre sustentabilidade empresarial e da prioridade entre as dimensões social ou ambiental da sustentabilidade.

A respeito das limitações enfrentadas durante a pesquisa, houve dificuldades no levantamento de fontes bibliográficas que abordassem a sustentabilidade no âmbito do empreendedorismo. Vale ressaltar a restrição inerente ao procedimento técnico utilizado (entrevista), a qual pode obter dados a partir do ponto de vista dos pesquisados.

Além disso, verificou-se a utilização de termos diferentes nas fontes em língua portuguesa (Sustentabilidade Empresarial) e em língua inglesa (Sustainable Entrepreneurship, traduzido pelos pesquisadores como Empreendedorismo Sustentável). A complementaridade das explicações dos autores sobre os termos levou os pesquisadores a adotá-los como sinônimos. 
Apesar dessas restrições, a pesquisa contribuiu com a expansão do conhecimento sobre Empreendedorismo Sustentável, um tema recente e ainda em construção. Foi possível traçar um cenário inicial sobre a implementação da sustentabilidade entre empreendedores incubados na Região Metropolitana de Fortaleza. Recomenda-se a realização de um estudo mais amplo e profundo que permita identificar o comportamento padrão das empresas incubadas.

\section{SUSTAINABLE \\ ENTREPRENEURSHIP: MULTICASE STUDY OF SUSTAINABILITY IMPLEMENTATION IN INCUBATED ENTREPRISES}

\begin{abstract}
The multicase study sought to examine the incorporation of the dimensions of corporate sustainability in incubated companies by checking the understanding of the entrepreneurs regarding business sustainability and identifying between the social and environmental dimensions of sustainability, which predominates as an emerging concern. This is an exploratory-descriptive research. From the literature survey, an interview script was developed, structured upon four constructs. We interviewed three of the four entrepreneurs attended by PARTEC, incubator companies NUTEC, aiming to extend the findings of the literature review. It was found that the definition of corporate sustainability most accepted only refers to economic and environmental dimensions, getting social background. However, they found themselves in difficulty as to understanding the subject among those consulted. Entrepreneurs prioritize the environmental dimension of the social in its activities. The organizations cannot be considered fully sustainable. However, it can be said that the solutions offered by them are sustainable as they allow the survival of organizations and nature, and generate positive and sustainable impact on society.
\end{abstract}

Keywords: Sustainable Entrepreneurship. Enterprises. Multicase Study.

\section{REFERÊNCIAS}

ABREU, F.; SWIRSKI, Y.; GONÇALO, C. Aprendizagem e criação de conhecimento em incubadoras. In: ENCONTRO DA ANPAD, 30., 2006, Salvador. Anais... Salvador: Anpad, 2006. p. 1-16.

ALMEIDA, F. Os desafios da sustentabilidade: uma ruptura urgente. Rio de Janeiro: Elsevier, 2007.

AUDY, J. L. N.; MOSCHETTA, R. A.; ZANELLA, V. H. B.; BARROS, M. B. Criação de uma incubadora de base tecnológica oriunda de projetos de pesquisa da Pontifícia Universidade Católica do Rio Grande do Sul dentro do "Habitat de Inovação" do parque tecnológico TECNOPUC. In: SEMINÁRIO NACIONAL DE PARQUES TECNOLÓGICOS E INCUBADORAS DE EMPRESAS, 13., 2003, Brasília. Anais... Brasília: UNB, ANPROTEC, 2003. p. 71-80.

BARBIERI, J. C.; CAJAZEIRA, J. E. R. Responsabilidade social empresarial e empresa sustentável: da teoria à pratica. São Paulo: Saraiva, 2009.

BOSZCZOWSKI, A. K.; TEIXEIRA, R. M. O empreendedorismos sustentável e o processo empreendedor: em busca de oportunidades de novos negócios como solução para problemas sociais e ambientais. Revista Economia \& Gestão da PUC Minas, Minas Gerais, v. 12, n. 29, p. 141-168, maio/ago. 2012.

BRITO, M. D.; BRUNSTEIN, J.; AMARO, R. A. Sustentabilidade, incubadoras de empresas e universidades: um olhar para a nova geração de empreendedores. In: ENCONTRO DA ANPAD, 38., 2014, Rio de Janeiro. Anais... Rio de Janeiro: Anpad, 2014. p. 1-16. 
CARDOSO, A. C et al. Incubadoras orientadas para o desenvolvimento sustentável: é possível? o caso do centro de incubação de empresas de tecnologias (CIETEC). Revista de Gestão Social e Ambiental, São Paulo, v. 2, n. 2, p. 69-87, maio/ago. 2008.

DALMORO, M. A visão da sustentabilidade na atividade empreendedora: uma análise a partir de empresas incubadas. Revista Gestão Organizacional, Santa Catarina, v. 2, n. 1, p. 87104, jan./jun. 2009.

DORNELAS, J. C. A. Empreendedorismo: transformando ideias em negócios. 3. ed. Rio de Janeiro: Elsevier, 2008.

ESTY, D. C.; WINSTON, A. S. Green to gold: how smart companies use environmental strategy to innovate, create value, and build competitive advantage. New Haven: Yale University Press, 2006.

GIL, A. C. Como elaborar projetos de pesquisa. 4. ed. São Paulo: Atlas, 2006.

GRECO, S. M. S. S. et al. Empreendedorismo no Brasil: 2008 - relatório executivo. Curitiba: IBPQ, 2009. Disponível em: $<$ http:// www.sebraepr.com.br/FCKeditor/userfiles/file/ NOVO $\% 20$ PORTAL/PESQUISAS/Gem $\% 20$ 2008.pdf>. Acesso em: 15 nov. 2014.

HISRICH, R. D.; PETERS, M. P. Empreendedorismo. 5. ed. Porto Alegre: Bookman, 2004.

IACONO, A.; ALMEIDA, C. A. S.; NAGANO, M. S. Interação e cooperação de empresas incubadas de base tecnológica: uma análise diante do novo paradigma da inovação. Revista de Administração Pública, Rio de Janeiro, v. 45, n. 5, p. 1485-1516, set./out., 2011.

LAVILLE, C.; DIONNE, J. A construção do saber: manual de metodologia da pesquisa em ciências humanas. Belo Horizonte: UFMG, 2008 .
LEIPZIGER, D. SA 8000: o guia definitivo para a nova norma social. Rio de Janeiro: Qualitymark, 2003.

MAHLER, D. The sustainable supply chain. Supply Chain Management Review, Framingham, p. 59-60, Nov. 2007.

MURPHY, P. J.; LIAO, J.; WELSCH, H. A conceptual history of entrepreneurial thought. Journal of Management History, Richardson, Texas, v. 12, n. 1, p. 12-35, 2006.

NUTEC - FUNDAÇÃO NÚCLEO DE TECNOLOGIA INDUSTRIAL DO CEARÁ. NUTEC Export. Disponível em: $<$ http://www. nutec.ce.gov.br/index.php/component/content/ article/6-assistencia/43416-nutec-export->. Acesso: 06 nov. 2014.

OLIVEIRA, M. A. L. SA 8000: o modelo ISO 9000 aplicado à responsabilidade social. Rio de Janeiro: Qualitymark, 2002.

OLIVEIRA, L. G. L. et al. Responsabilidade social corporativa: estudo comparativo das normas socioambientais. Contextus - Revista Contemporânea de Economia e Gestão, Fortaleza, v. 5, n. 2, p. 41-54, 2007.

PARRISH, B. D. Sustainability-driven entrepreneurship: principles of organization design. Journal of Business Venturing, United States, v. 25, n.5, p. 510-523, 2010.

PINSKY, V. C. et al. A. Inovação Sustentável: uma perspectiva comparada da literatura internacional e nacional. Revista de Administração e Inovação, São Paulo, v. 12, n. 3, p. 226250, jul./set. 2015.

ROMANINI, V. O valor da sustentabilidade. Exame PME, São Paulo, 12 jul. 2007. Disponível em: <http://portalexame.abril.com.br/ revista/pme/edicoes/0009/m0133114.html>. Acesso em: 25 ago. 2014. 
SEBRAE - SERVIÇO BRASILEIRO DE APOIO ÀS MICRO E PEQUENAS EMPRESAS. Fatores condicionantes e taxas de sobrevivência e mortalidade de micro, pequenas e médias empresas no Brasil 2003 - 2005. Brasília, 2007.

SILVA, N. V.; TOBIAS, R. A importância do marketing para a incorporação da sustentabilidade da marca Natura. 2007. Disponível em: <http://www.portaldomarketing.com.br/ Artigos/Importancia_do_marketing_para_a Incorporacao_da_sustentabilidade_da_marca_ natura.htm>. Acesso em: 25 ago. 2014.

VAN BELLEN, H. M. Indicadores de sustentabilidade: uma análise comparativa. 2. ed. Rio de Janeiro: FGV, 2007.

VEDOVELLO, C. Aspectos relevantes de parques tecnológicos e incubadoras de empresas. Revistas do BNDES, Rio de Janeiro, v. 7, n. 14, p. 273-300, 2000.

YOUNG, W.; TILLEY, F. Can businesses move beyond efficiency? The shift toward effectiveness and equity in the corporate sustainability debate. Business Strategy and the Environment, United Kingdom, v. 6, n. 15, p. 402-415, 2006. 